\title{
A Cross-Cultural Examination of Curriculum and Sexuality Outcomes in Primary School
}

\author{
Róbert Osad'an - Yasmin Safir *
}

\begin{abstract}
In this paper, sexuality will be examined with regards to the parental attitudes as well as the public curriculum of various countries across the globe at the primary school level. The outcomes will be explored in relation to the type of education and dissemination of information provided to children and conclusions will be made based on these outcomes. The countries of Canada, the United States, Kenya, Australia and Ghana will be studied in detail. The outcomes will be looked at within some global comparison and proportions.
\end{abstract}

Key words: sexuality, outcomes, cross-cultural, parental attitudes.

\section{Introduction}

Sexuality is a topic that is often taboo in many cultures and families, especially when it comes to childhood. Many parents regard sexuality as a private topic that requires private discussions. In some families, it is often not explored enough or at all. Yet other parents provide meaningful information to their children when the topics arise (Parsons, Butler, Kocik, Norman and Nuss, 1998; Sunder, Ramos, Short, and Rosenthal, 2006). There is a recent shift for social changes within some countries which includes addition to the curriculum to include younger age groups and exploring ways in which to present and share that information with children.

This paper will examine the literature around parental attitudes towards sex education in some countries. Moreover, the public school curriculum will be looked at on a large scale, with regards to sex education. Finally, the outcomes will be considered based on different methods of information sharing with children and youth.

\section{Discussion}

It should be noted that the differences in cultures vary vastly by individual and this section in no means exists to stereotype people by culture or country, but simply to examine the differences between population and federal regulations.

\footnotetext{
* Róbert Osad'an, Comenius Universtity in Bratislava, Bratislava, Slovakia; osadan@fedu.uniba.sk

Yasmin Safir, Freelance Researcher, Toronto, Canada; earlyinterventionists@yahoo.ca
} 
Since there is a going consensus that family values and public education should be on the same page and work together for continuity and effectiveness in children's lives as well as to dissuade confusion for them, then the differences and similarities on a wide scale will be looked at. For purposes of clarification, the word culture will be synonymous with country. This is presented for the purpose of statistical analysis and measurement in the population that will be contrasted against the public education attitude in the topic of sexuality in childhood.

Within the Kuria community in southwestern Kenya, the principles of sexuality are defined through the purpose of procreation and child-bearing (Prazak, 2000, p. 82). Advocating reproduction as a chief goal, grandparents serve as educators, mainly stressing the girls' duties to husbands. A young girl growing up in a community of Kenya is educated on the basic skills mandated for eligibility of marriage, which include cooking, hygiene, cleaning, and motherhood. All of these skills are communicated in the Home Science classes taught in school, yet the lack of sexual instruction in schools remains a present-day dilemma (Prazak, 2000 , p. 82). The details of what happens between a man and a woman are usually shared to the girls by a married woman (Prazak, 2000, p. 82). The majority of men in African societies do not talk about sex because discussion of it is viewed as diminishment in manliness and control (Prazak, 2000, p. 85).

In a study conducted in Ghana of 100 parents from various backgrounds, the results indicated that about $58 \%$ of parents have an unfavourable attitude towards sex education at the primary level (Nyarko, Adentwi, Asumeng and Ahulu, 2014, p. 25). Of the parents who held favourable attitude; $81 \%$ indicated that children are exposed a lot these days, $17 \%$ admitted that sex education will be helpful to the children and $2 \%$ said children ask questions about sex anyway and needed to be provided with answers (Nyarko, Adentwi, Asumeng and Ahulu, 2014, p. 22). The Ghanaian government's attitude toward sex education is best described as ambivalent because, though the subject is officially part of the school curricula, it is not "effectively taught" in practice (Osei, 2009). There was no document found guiding principles on sex education in Ghana, rather documents to call for sex education to be put into place by various community leaders.

In a study conducted in some rural communities in Canada, parents filled out a questionnaire regarding sex education. Most parents (82\%) were also in favour of school-based sexual health education that begins in the primary grades and continues through the senior grades of high-school. Parents took a pluralistic approach to teaching about the moral dimensions of sexual health with $81 \%$ strongly agreeing or agreeing about the importance for sexual health education to recognize and respect the different moral beliefs about sexuality that may exist in their community (McKay et. al, 1998). Studies conducted in different parts of Canada showed consistently that $85 \%$ of parents agreed with the statement that sex education should be provided in schools. The curriculum 
varies across the country. Four out of ten provinces require the curriculum to be very detailed and structured into age groupings beginning at the grade one level and continuing through until high school (Ophea, 2010).

In the United States, the majority of parents believes that some sort of comprehensive sexual education program should be taught in the schools, ranging from 89\%-95\% approval; this support has been found across all demographic categories of parents (Eisenberg et al., 2008; Kirby, 2007; McKay et al., 1998). Many parents who support a comprehensive sexual education believe that most topics regarding sexual health should be first introduced either in the primary grades or during middle school (Eisenberg et al., 2008; McKay et al., 1998). Across the states, there is considerable variability in requirements for education as well as funding provided for programs. Almost all students in the U.S. receive some form of sex education at least once between grades 7 and 12; many schools begin addressing some topics as early as grades 4 or 5 (Landry, Singh and Darroch, 2000). There was no information found to corroborate any promotion of teaching sexual education before grades 4 or 5 .

In Western Australia, the Parent Sexual Health Resources project was conducted and statistics measured regarding parents' attitudes towards sex education. Some indicated that they had discussed human sexuality with their children from a young age, and were open to answering questions, while others waited until they thought it was the 'right time' to raise the subject. Those who waited tended to express the view that they would only answer questions when they arose, and were concerned about protecting their children from too much information about sex. This approach was recognised as problematic because some children never ask questions (Department of Health, Western Australia, 2010).

The Victorian Department of Education (in Western Australia) policy guidelines state that sex education is compulsory for school students from Prep to Year 10. Sex Education Australia (SEA) is an organization which provides programs to public schools that are devised in accordance with the Victorian Education Learning Standards (VELS). The primary sessions cover topics for year 5 and 6 students in an age appropriate manner. The SEA can also provide younger students with education that is appropriate to their age (Walsh, 2011, p. 44).

Now that some countries are discussed, the outcomes will be looked upon based upon current research, statistics and global policies. Talking about sexuality in primary grades openly enables children to be more confident in discussing sexual matters (Wellings et al., 1995, p. 417). Offering comprehensive and flexible sexual education programs has been found to delay the age when young people become sexually active (Wellings et al., 1995, p. 419). A recognized public health society in Canada found out that children whose parents discuss values and attitudes towards sexuality and who receive good sexuality education at school are more likely to delay sex and less likely to have an unplanned pregnancy or a sexually transmissible infection. Reducing these negative outcomes is not the only purpose of sex education but it is an important one 
(Society of Obstetricians and Gynaecologists of Canada, 2008). Another positive outcome of early sex education is that when young people do become sexually active, they are more likely to protect their sexual health by choosing fewer partners and using contraception (UNAIDS, 1997).

Yet more research has shown that parental communication with the child, particularly between a mother and daughter, will not only delay sexual intercourse and create negative attitudes regarding pregnancy, but also decrease the likelihood of the youth having unprotected sex and decrease the number of sexual partners (Parsons, Butler, Kocik, Norman and Nuss, 1998, Sunder, Ramos, Short and Rosenthal, 2006). Thus, the content and quality of parentchild communication may have an effect on delaying or accelerating the time line for sexual initiation (Bersamin et al., 2008).

A correlation often exists between the amount of education and the rate of teen pregnancy. A study from the National Survey of Family Growth showed that students are half as likely to get pregnant between the ages of 15 and 19 after going through a sex-education class. In Germany, where there are comprehensive sex education programs put into place, there is the lowest birth rate among 15 - to 19 -year-olds - only 11.7 per 1000 people, compared to 27.8 births per 1,000 people in the UK, and 39.0 births per 1,000 people in Bulgaria, which incidentally has the highest birth rate in Europe (Spiegel magazine, 2006).

\section{Conclusions}

A number of countries seem to recognize the importance of discussing sexuality with children in primary grades. The outcomes show that it is advisable and necessary to provide children with comprehensive, regulated age-appropriate information. In their book "Diversity and Difference in Early Childhood Education", the authors call for recognizing children as important contributors to society, which means arming them with information they can use in the everyday world (Robinson and Jones, 2006, p. 9). As we live in complex times, new frameworks are needed in education in a multi-faceted world (Yelland, p. 5).

In 1986, the World Health Organization (WHO) stated that sexuality is an integral part of everyone's personality: of man, woman and child. It is a basic need and aspect of being human that cannot be separated from other aspects of life and it influences thoughts, feelings, actions and interactions and thereby our mental and physical health (Langfeldt and Porter, 1986).

Based on all of these facts, research, statistics and recommendations, it is fair to state that to promote the sexual health of every child, they should be exposed to sex education which is age-appropriate and regulated to enrich their lives from a young primary-age. Enrichment of physical and mental health by preventing teenage pregnancies, STDs, etc. and promotion of the positive attributes aforementioned. It is also fair to state that parents should be involved in the decision making process and also educated on the positive outcomes that 
regulated sex education may bring. Finally, parents need to be involved and educated on the ways of handling and initiating discussions with their children regarding sex education since it should be a cohesive process for the child.

\section{References}

BERSAMIN, M., TODD, M., FISHER, D. A., HILL, D. L., GRUBE, J. W. and WALKER, S. Parenting practices and adolescent sexual behavior: A longitudinal study. Journal of Marriage and Family, 70, 2008, pp. 97-112.

EISENBERG, M. E., BERNAT, D. H., BEARINGER, L. H. and RESNICK, M. D. Support for comprehensive sexuality education: Perspectives from parents of school-age youth. Journal of Adolescent Health, 42, 2008, pp. 352-359.

KIRBY, D. Emerging answers 2007: Research findings on programs to reduce teen pregnancy and sexually transmitted diseases. The National Campaign to Prevent Teen and Unplanned Pregnancy [online]. 2007 [viewed 20 October 2014]. Available from: http://www.thenationalcampaign.org/EA2007/EA2007_full.pdf.

LANGFELDT, T., PORTER, M. Sexuality and family planning: Report of a consultation and research findings. Copenhagen: World Health Organization, Regional Office for Europe, 1986.

NYARKO, K., ADENTWI, K. I., ASUMENG, M. and AHULU, L. D. Parental Attitude towards Sex Education at the Lower Primary in Ghana. International Journal of Elementary Education, 3, 2014, 2, pp. 21-29.

LANDRY, D. J., SINGH, S. and DARROCH, J. E. Sexuality Education in Fifth and Sixth Grades in U.S. Public Schools, 1999. Family Planning Perspectives, 32, 2000, 5 .

MCKAY, A., PIETRUSIAK, M. and HOLOWATY, P. Parents' opinions and attitudes towards sexuality education in the schools [online]. The Canadian Journal of Human Sexuality, 7, 1998, June [viewed 21 October 2014]. Available from: http://www.biomedsearch.com/article/Parents-opinions-attitudes-towardssexuality/21158933.html.

OSEI, A. Sex Education in Ghanaian Society: The Skeleton in the Cupboard [online]. 2009 [viewed 20 October 2014]. Available from: ashesi.edu.gh/images/academics/writing/center/09_osei_essay.pdf.

PARSONS, J. T., BUTLER, R., KOCIK, S., NORMAN, L. and NUSS, R. The role of the family system in HIV risk reduction: Youth with hemophilia and HIV infection and their parents. Journal of Pediatric Psychology, 23, 1998, pp. 5765.

PRAZAK, M. Talking about sex: Contemporary Construction of Sexuality in Rural Kenya. Africa Today, 47, 2000, 3/4, pp. 82-97.

ROBINSON, K. H., JONES DIAZ, C. Diversity and difference in early childhood education. London: McGraw-Hill International, 2006. 
SUNDER, P. K., RAMOS, S., SHORT, M. B. and ROSENTHAL, S. L. Adolescent girls' communication with mothers about topical microbicides. Journal of Pediatric and Adolescent Gynecology, 19, 2006, pp. 373-379.

WALSH, J. Talk soon. Talk often: a guide for parents talking to their kids about sex. Western Australia Sexual Health and Blood-borne Virus Program, Perth, 2011.

WELLINGS, K., WADSWORTH, J., JOHNSON, A., FIELD, J., WHITAKER, L. and FIELD, B. Provision of sex education and early sexual experience: the relation examined. British Medical Journal, 1995, 311, pp. 417-20.

YELLAND, N. Critical issues in early childhood education. McGraw-Hill International, 2005.

http://data.unaids.org/Publications/IRC-pub01/jc010-impactyoungpeople_en.pdf [viewed 20 October 2014].

http://www.ghana.gov.gh/index.php/component/search/?searchword=sex\%20ed ucation\&searchphrase $=$ all\&start $=20$ [viewed 20 October 2014].

https://www.ophea.net/sites/default/files/pdfs/advocacy/ADV_SexEdReportFIN AL_31MY13.pdf 2010.

http://www.sexualityandu.ca/home_e.aspx [viewed 14 October 2014].

http://www.spiegel.de/international/european-sex-survey-teens-from-germanyiceland-ditch-virginity-early-a-454492.html. 